\title{
Zur Chemie des Polyporus frondosus Fl. Dan.
}

\author{
(vorläufige Mitteilung) \\ von \\ M. Bamberger und A. Landsiedl. \\ Ausgeführt im Laboratorium für allgemeine Experimentalchemie an der \\ k. k. Technischen Hochschule in Wien.
}

(Vorgelegt in der Sitzung am 6. Juli 1911.)

Aus dem weingeistigen Auszug des frischen Pilzes konnte durch Fällung mittels Ammoniak eine basische stickstoffhältige Substanz abgeschieden werden, die gereinigt ein weißes feinkrümeliges Pulver darstellt, das sich beim Erhitzen auf dem Platinblech bräunt und unter Hinterlassung schwer verbrennlicher Kohle zersetzt, ohne vorher zu schmelzen.

Die Substanz, welche nicht krystallisiert erhalten werden konnte, ist unlöslich in Wasser, Alkohol, Äther, Chloroform, Aceton, Essigsäure, Petroläther und Benzol, dagegen leicht löslich in verdïnnten Mineralsäuren, mit denen sie zum Teil sehr gut krystallisierende Salze bildet. So scheidet sich das Chlorhydrat beim langsamen Verdunsten der salzsauren Lösung in schönen, wasserhellen, rektangulären Säulen und quadratischen Tafeln aus. Ähnliche Krystallformen zeigt das Bromhydrat.

Die wässerige Lösung des Chlorhydrates gibt mit Pikrinsäure ein in derben Spießen anschießendes Pikrat und mit Platinchlorid ein körnig sich ausscheidendes Platinsalz. Ein Goldsalz konnte bisher nicht erhalten werden.

Besonders charakteristisch ist das Sulfat, das aus der Lösung der Substanz in heißer verdünnter Schwefelsäure in feinen glasglänzenden Nadeln sich abscheidet.

Das sehr leicht lösliche Nitrat bildet eine strahlig krystallinische Masse. 
642 M. Bamberger u. A. Landsied1, Polypons frondosts F1. Dan.

Gegenüber der Einwirkung von Wärme zeigt der Körper eine bemerkenswerte Beständigkeit. Proben des Chlorhydrates und Sulfates begannen erst über $300^{\circ} \mathrm{C}$. sich merklich zu bräunen.

Da nur sehr wenig Material zur Verfügung stand, waren wir nicht in der Lage, eine Elementaranalyse vorzunehmen, und müssen wir die nähere Identifizierung der Verbindung einer späteren Untersuchung vorbehalten.

Herrn Hofrat Dr. K. Toldt, der die Güte hatte, uns einige Exemplare des als Speise geschätzten Pilzes zur Verfügung zu stellen, gestatten wir uns, an dieser Stelle den verbindlichsten Dank zum Ausdrucke zu bringen. 